\title{
University students developing imaginative problem solving skills - the case of food engineering
}

Torrecilla, José S. ${ }^{\text {a }}$ Aguado, Roberto ${ }^{\text {b}}$; Tijero, Antonio ${ }^{\text {a }}$; Ballesteros, Menta ${ }^{\text {b; }}$ Moral, Ana ${ }^{\text {b; Lastra, Miguel }}{ }^{\text {a }}$

${ }^{a}$ Departamento de Ingeniería Química. Universidad Complutense de Madrid, Spain, ${ }^{\text {b}}$ Departamento de Biología Molecular en Ingeniería Bioquímica, Universidad Pablo de Olavide, Sevilla, Spain.

\begin{abstract}
In this summary, a teaching technique to learn relevant food engineering and chemical engineering concepts has been presented. This method has been tested experimentally for the last two years in a class which belongs to the Food Science and Technology Bachelor's Degree in the Complutense University of Madrid in Spain, and it is based on the induction of complex concepts through comprehensive everyday examples. More than $90 \%$ of students have adequately been able to extrapolate the knowledge acquired to other technical fields.

The application of this method has resulted in an increased rate of passing exams and classes, as well as a higher attendance percentage. And most importantly, the students are having fun while learning. Furthermore, this great experience has encouraged some students to collaborate in the development of this teaching approach.
\end{abstract}

Keywords: Creative Learning; Induction Didatic Method; Engineering. 


\section{Introduction}

It is true and clear that all scientists need imagination. We (scientists) need it to come up with hypotheses to problematic phenomena, to devise how to get the evidence which is required, to figure out potential sources of error, to modify the initial conjecture if it is not corroborated by evidence, or to suggest a different one (Haack, 2007). Science education must convey not only facts and skill, but also virtues required by any inquirer: imagination, persistence, care, reason, honesty.

These ideas are far from being new. The role of creativity in learning has motivated countless research papers and books since the middle of the 20th century, and more than 150 thousand publications deal with creativity in the context of science education (Hadzigeorgiou et al., 2012). Imaginative problem solving should be encouraged in university staff, as it enhances divergent thinking abilities among students (Alharji, 2010; Shen, 2012).

Nonetheless, even as of today, there is evidence that students fail to see science as something inherently imaginative, that "they do not view science in general as a creative endeavor" (Hadzigeorgiou et al., 2012). This is undoubtedly an education failure, and it comes at no surprise if we take into account that students of science from any level are, in most cases, solely evaluated by external verification. This evaluation is usually carried out through consultation of textbooks, guidelines, standards, etc., that the pupil has been asked to study. This leads students to misunderstand science as a discipline in which recall of facts and technical/practical skill is preferred over "the ability to extend and reconfigure understanding when confronted with novel problems" (Schmidt, 2011).

Even more worrying is to realize than many teachers and practitioners of research hold the belief that there can only ever be one "scientific" way of knowing (Kind and Kind, 2007), still rooted in the thoughts of the first Positivist thinkers. This nonsense seems to indicate that most scientists pay as much attention to philosophy of science as stars and planets to astronomical papers.

\section{Imagination in the theory of knowledge}

Likely, the reactionary conceptualization of science as facts and methodology comes from a real necessity - the urge to demarcate reliable empirical science from a priori metaphysics, legends, proverbs, traditional know-how, religion, and superstition. Thus, inductivism was born to free the scientist from preconceptions. According to Bacon in 1620, everything starts with observation of nature (Bacon and Devey, 2016). A law follows, not preceeds, careful experimentation. General observation comes before a modest law. Extensive observation comes before a broad law, but theory never exceeds experimentation. 
Developing the motivations of inductivism in a modern world, Comte, in the middle of the 19th century, creates what he calls "positive philosophy" (Comte, 1988). As an enemy of metaphysics and theology, he compels us to focus on the positive: real, perceptible, useful, accurate, sensible, and constructive. Although the Positivist battle against superstition must be appreciated, these views on science education are nothing short of reactionary. Opinion is out of place in scientific research, imaginative theorizing and free inquiry are mercilessly shunned. He called irresponsible the suggestions of Russeau, whose opinion was that a teacher should give his pupil freedom, so he can find love and motivation to do things by himself.

Important voices against the theory of induction arose in the 20th century. Einstein and Infeld (1936): "Physical concepts are free creations of the human mind, and are not, however it may seem, uniquely determined by the external world". As mere anecdotes, Einstein imagined himself flying at light speed and visualizing the objects that he could see, and Kekule literally imagined the shape of benzene prior to experimentation (Ho et al., 2013; Wang et al., 2015). But these anecdotes can only illustrate the debate that took place in the field of the theory of knowledge.

The so-called "problem of induction", i.e., the lack of justification for generalizing about the properties of a class of objects based on some number of observations, was first described by Hume, but he stated that science could only be inductive anyway. In the epistemological battle of the 20th century, Carnap (1950) dedicated appreciable efforts to justify the place of inductive logic in science, but Popper (1959) shunned them all. In The Logic of Scientific Discovery, he states: "[A] theory of induction is superfluous. It has no function in a logic of science. [...] This appraisal of the hypothesis relies solely upon deductive consequences (predictions) which may be drawn from the hypothesis: There is no need even to mention 'induction'." Science is not born from perception, science is "an adventure of the human spirit". A scientist must be creative, imaginative, daring and, above all, critical. Theories are not confirmed or verified. They may be falsified and rejected or corroborated in the absence of falsification.

Popper's views on education are anything but timely. In Unended Quest, he claims: "If I thought of a future, I dreamt of one day founding a school in which young people could learn without boredom, and would be stimulated to pose problems and discuss them; a school in which no unwanted answers to unasked questions would have to be listened to; in which one did not study for the sake of passing examinations." (Popper, 2002). We hope to rescue the idea that pupils should not study for the sake of passing examinations. They should be ready to confront novel problems with imagination and bravery.

A new general didactic method has been tested and compared against classic ones in the "Food Engineering" context during the last two academic courses. This core class belongs 
to the $3^{\text {rd }}$ level of classes of the Food Science and Technology Bachelor's Degree in the Complutense University of Madrid in Spain. The comparison was done using a survey where the students shared their opinions on the matter.

\section{Examples of imaginative problem solving in food engineering}

Most of our students of Food Engineering have many problems in understanding the basis of the transportation of properties. To overcome it, different everyday examples were used to induce the concepts in the students. For instance, the flow of fluids can be explained by observing how sailplanes or small airplanes fly, figure 1. The difference of pressures and friction on the wings of the airplane helps us explain the concept of friction force and pressure. Another interesting example consists of describing the thermal energy interchange using domestic heaters.

Once the student comprehends the concept provided by these examples, the underlying law or theory is easier to understand. This method has been implemented while teaching 154 students, and more than $90 \%$ of them were able to understand and extrapolate the knowledge gathered to other systems. This great experience has even encouraged some students to collaborate in improving the teaching examples.

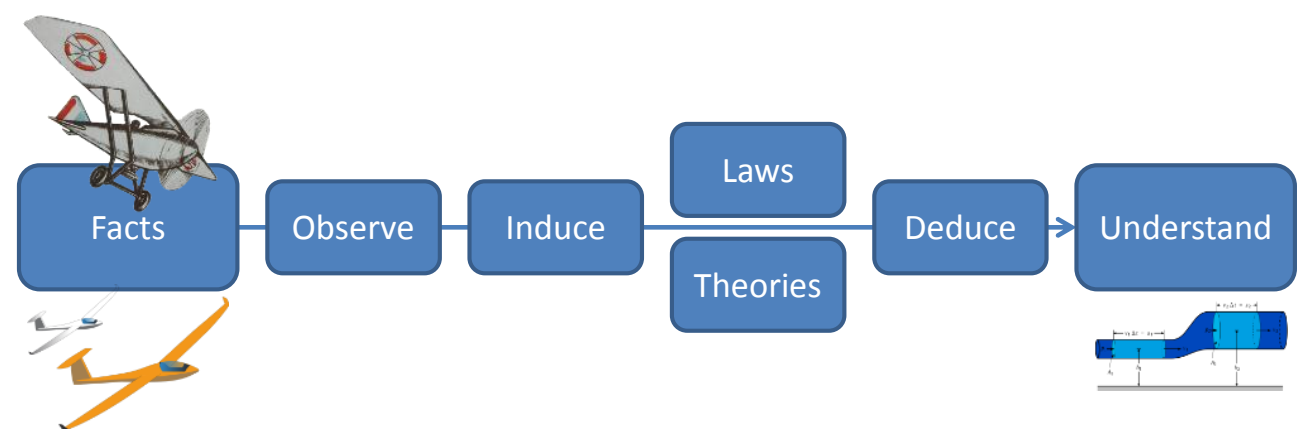

Figure 1. Induction method applied

It has been shown that students learn chemical engineering concepts better if given tools to reproduce physically the goals of the problem, such as 3D puzzles, mirrors, Lego® pieces, balloons, etc. (Raviv, 2004). In addition to this, most of the students (96\%) prefer this methodology over other more common ones. As a consequence of it, the attendance is also increasing. All of these facts result in higher passing rates in these two classes, meaning that students enjoying the classes is correlated with their success in them. 
As a consequence of these results, this teaching approach is being applied to other subjects in different bachelor's degree programs and different Spanish universities.

\section{References}

Alhajri, S.A. (2010). The importance of creativity in teaching graphic design in Arab world. Design Principles and Practices: An International Journal, 4(1), 59-69.

Bacon, F., \& Devey, J. (2016). Novum Organum - True suggestions for the interpretation of nature. Altermünster: Jazzybee Verlag.

Carnap, R. (1950). Logical Foundations of Probability. Chicago: The University of Chicago Press.

Comte, A. (1988). Introduction to positive philosophy. Indianapolis: Hackett Publishing.

Einstein, A., \& Infeld, L. (1938). The evolution of physics. Cambridge: Cambridge University Press.

Haack, S. (2007). Defending Science —within Reason. New York: Prometheus Books.

Hadzigeorgiou, Y., Fokialis, P., \& Kabouropoulou, M. (2012). Thinking about Creativity in Science Education. Creative Education, 3(5), 603-611.

Ho, H.C., Wang, C.C., \& Cheng, Y.Y. (2013). Analysis of the Scientific Imagination Process. Thinking Skills and Creativity, 10, 68-78.

Kind, P.M., \& Kind, V. (2007). Creativity in science education: Per-spectives and challenges for developing school science. Studies in Science Education, 43, 1-37.

Popper, K.R. (1959). The Logic of Scientific Discovery. London: Hutchinson \& Co.

Popper, K.R. (2002). Unended Quest: An Intellectual Autobiography. London: Routledge.

Raviv, D. (2004). Hands-on Activities for Innovative Problem Solving. Proceedings of the 2004 American Society for Engineering Education Annual Conference \& Exposition.

Schmidt, A.L. (2011). Creativity in science: tensions between perception and practice. Creative Education, 2(5), 435-445.

Shen T.L. (2012). Inspiring the creativity and imagination of university students during creative curriculum by teaching design. Procedia-Social and Behavioral Sciences, 45, 615-620.

Wang, C.C., Ho, H.C., \& Cheng, Y.Y. (2015). Building a learning progression for scientific imagination: A measurement approach. Thinking Skills and Creativity, 17, 1-14. 